\title{
A LINGUAGEM QUÍMICA E O ENSINO DA QUÍMICA ORGÂNICA\#
}

\author{
Nídia Franca Roque* e José Luis P. B. Silva
}

Instituto de Química, Universidade Federal da Bahia, Campus Universitário de Ondina, 40170-115 Salvador - BA, Brasil

Recebido em 14/1/08; aceito em 4/3/08; publicado na web em 9/4/08

\begin{abstract}
CHEMICAL LANGUAGE AND ORGANIC CHEMISTRY TEACHING. The importance of chemical language and specifically of molecular models and their representations in the development of chemistry is discussed. Structural formulas are projections of molecular models used as a specific language by chemists. The meaningful learning of chemistry requires knowledge of this language. The use of these analogical symbols without the necessary understanding engenders difficulties for the learning of chemistry.
\end{abstract}

Keywords: molecular models; chemical language; chemistry teaching.

\section{INTRODUÇÃO}

Helena Maria C. Ferraz tornou-se conhecida como pesquisadora na área de síntese orgânica e foi também uma professora muito querida por seus alunos. Com ela dividi (N. F. Roque) algumas vezes disciplinas de química orgânica para alunos de graduação e, embora tivéssemos algumas divergências na abordagem dos conteúdos, em um aspecto concordávamos cem por cento: a necessidade da compreensão da linguagem química. Esta é uma homenagem que prestamos à Professora Helena Ferraz.

Em seu livro "O que é ciência afinal", Chalmers' discute a dificuldade em se definir ciência e, conhecimento científico. Considerando que um conjunto de conhecimentos, sobre um dado assunto, adquiridos através de estudos teóricos e/ou experimentais é um conhecimento científico, o químico trilhou um caminho próprio entre as ciências enfrentando a dificuldade de interpretação e descrição dos fenômenos de transformação da matéria, o que levou à criação de uma linguagem química. As transformações materiais - reações químicas - fazem parte dos processos naturais, fazendo parte do dia-a-dia do ser humano desde tempos imemoriais. Um dos fenômenos químicos mais comuns é a transformação do dióxido de carbono $\left(\mathrm{CO}_{2}\right)$ e da água $\left(\mathrm{H}_{2} \mathrm{O}\right)$ presentes na atmosfera em folhas, galhos, raízes, frutos e flores, em suma, no corpo dos vegetais. A combustão é uma outra transformação da matéria também muito comum. Entre as reações de combustão estão as queimas da lenha, do carvão, de combustíveis de carros, de ônibus, de caminhões e de gás de cozinha. A corrosão de metais, como a do ferro produzindo a ferrugem é, também, uma transformação facilmente observável. Essas últimas são transformações da matéria inanimada ao reagirem com o oxigênio presente na atmosfera.

Então, por que somente há duzentos anos surgiu uma teoria que explica e descreve, satisfatoriamente, os fenômenos quími$\cos$ ?

Várias teorias para explicar a formação e a transformação da matéria foram sugeridas, no transcorrer das civilizações. A mais duradoura, defendida pelo filósofo grego Aristóteles (384 a.C.-322 a.C.), proposta por Empédocles (490 a.C.-430 a.C.) admitia que todos os objetos e seres seriam compostos por proporções diferentes de quatro elementos: terra, ar, água e fogo. ${ }^{2}$ Embora essa teoria

\#Artigo em homenagem à Profa. Dra. Helena M. C. Ferraz

*e-mail: nifroque@ufba.br tenha sobrevivido cerca de 2.000 anos ela e muitas outras não conseguiram explicar racionalmente os fenômenos químicos.

A teoria atômica empregada, hoje, para explicar os fenômenos químicos, embora tenha tido suas raízes ainda na Grécia antiga, com as idéias de Leucipo e Demócrito (460 a.C.- 370 a.C.), e permeado as várias civilizações até a Idade Moderna, só começou a ter sucesso há cerca de 200 anos atrás com as argumentações de Dalton $^{2}$ (1766-1844).

Uma grande dificuldade para o entendimento dos fenômenos químicos está em se conhecer a constituição das substâncias que formam os organismos vivos e os objetos. O mundo material em que vivemos é percebido pelos animais através dos seus sentidos. Essa percepção é, no entanto, limitada, e foi superada com a descrição das substâncias em termos atômicos. O átomo veio fundamentar teoricamente a experiência dos sentidos, possibilitando uma descrição mais ampla e profunda do mundo material, justificando sua enorme diversidade. Hoje, aceitamos a matéria como constituída por substâncias que por sua vez são compostas por átomos, que se ligam formando moléculas ou íons. Átomos isolados só existem em alguns gases, conhecidos como gases nobres. Outros átomos se unem de uma forma diferente formando os metais. Por serem partículas muito pequenas, as porções de matéria que percebemos correspondem a aglomerados de quintilhões, ou mais, de átomos.

Átomos e moléculas têm estruturas reais que, no entanto, não podem ser percebidas através dos sentidos. Como estudar o imperceptível? A correlação entre o comportamento dessas minúsculas partículas, que fazem parte do microcosmo, e as propriedades das substâncias pertencentes ao sistema macroscópico foi e continua sendo um grande desafio da ciência química e, conseqüentemente, do ensino de Química. Como vencê-lo?

Para estabelecer essa correlação o homem precisou criar uma linguagem para discutir o microcosmo, ou seja, os átomos, íons e moléculas. ${ }^{3}$ E toda linguagem, já nos ensinou Vigotski, desenvolve-se na mesma medida que as estruturas do pensamento evoluem do concreto para o abstrato e vice-versa. ${ }^{4}$ A linguagem da Química descreve através de modelos, representados por fórmulas estruturais, equações, gráficos e figuras, as coisas do mundo como compreendidas pelo químico. As Ciências Naturais, e a Química, em particular, fazem extensivo uso de modelos, ou seja, representações simplificadas ou idealizadas de um mundo real. ${ }^{5}$ Para estudar e entender a ciência química é necessário em primeiro lugar aprender essa linguagem. As dificuldades de aprendizagem da lingua- 
gem da química estão associadas à distinção em relação à linguagem comum, ${ }^{6}$ à sua especificidade quase hermética ${ }^{7} \mathrm{e}$, muito provavelmente, às dificuldades em se estabelecer as necessárias relações entre os entes químicos do mundo microscópico e do macroscópico.

\section{Contribuições da química orgânica para a linguagem química}

A idéia do átomo como uma partícula indivisível permaneceu até o início do século XX, quando as evidências da existência de partículas com cargas na sua constituição foram detectadas. A partir dessas evidências vários modelos para a configuração do átomo foram propostos até chegarmos no modelo atualmente aceito. Por incrível que pareça, as fórmulas estruturais e modelos moleculares surgiram antes mesmo das concepções dos modelos atômicos. Aceita a idéia da constituição atômica da matéria, era fundamental conhecer como os átomos se uniam constituindo as moléculas.

Por volta de 1850 a química orgânica tornava-se uma especialidade dentro da química. A falta de homogeneidade dos pesos atômicos, dos nomes e das fórmulas moleculares, além do grande número de isômeros observados para os compostos orgânicos, tornava a comunicação dos trabalhos na área bastante difícil e, com isto, o seu desenvolvimento era prejudicado.

Em 1860 era urgentemente necessária uma homogeneidade na linguagem da química orgânica. Couper havia tido a excelente idéia de representar as ligações por traços ou pontos e Kekulé, Loschmidt, Gerhardt, Kolbe, entre outros químicos, haviam tentado estabelecer fórmulas gráficas que representassem os compostos orgânicos. ${ }^{8}$ Estas eram, no entanto, ou ambíguas ou muito complexas para serem usadas e, desta forma, não foram aceitas. Nesta época, o ácido acético, por exemplo, tinha dezenove diferentes representações, inclusive com diferentes números de átomos de carbono, hidrogênio e oxigênio.

A linguagem escrita e falada dos compostos orgânicos só começou a ser organizada após o Congresso de Karlsruhe (1860). ${ }^{9}$ Durante o Congresso não houve consenso na maneira de representar os compostos orgânicos. No entanto, um trabalho levado por Cannizzaro, sem repercussão durante o evento, foi distribuído para vários participantes que, após o lerem, aceitaram seus argumentos. Cannizzaro trazia de volta a hipótese de Avogadro, mostrando que ela poderia ser útil na diferenciação entre os conceitos de átomos e moléculas e uma defesa dos pesos atômicos do carbono como 12 , do oxigênio como 16 e do hidrogênio como 1, sugeridos por Laurent e Gerhardt e apoiados por Kekulé.

A precisão da análise elementar, idealizada por Lavoisier e aperfeiçoada por Liebig e Dumas, a homogeneização dos pesos atômicos e a determinação das fórmulas moleculares trouxeram uma primeira coerência à linguagem e à representação dos compostos orgânicos. As estruturas moleculares começaram a ser representadas por letras caracterizando os átomos e traços representando as ligações. No caso das estruturas cíclicas, elas eram representadas por desenhos de poliedros como a do benzeno, proposta por Kekulé.

\section{Modelos moleculares}

Ainda em 1865 A. W. Hoffmann apresentou, em uma conferência, modelos moleculares confeccionados com bolas e varas de madeira, ${ }^{8}$ salientando a importância do conhecimento da estrutura molecular.

Naquele momento, o grande desafio era a determinação da constituição da molécula, ou seja, a determinação do número de átomos dos elementos presentes e a conectividade entre eles. Assim, os modelos moleculares eram rígidos e representados em duas dimensões. O desafio da terceira dimensão das moléculas só surge após a descoberta de Pasteur do desvio do plano da luz polarizada provocado pelos ácidos tartáricos, aliada à forma tetraédrica proposta para o átomo de carbono por van’t Hoff e Le Bell. A partir daí tornou-se necessário imaginar e representar as moléculas em três dimensões. Tarefa difícil que exigiu a elaboração de modelos moleculares, que passaram a ser construídos, não apenas com bolas e varetas, mas também com bolas e molas. Hoje, modelos virtuais somam-se aos demais, constituindo uma nova ferramenta no estudo da química.

A analogia entre os modelos e as estruturas moleculares facilita o estudo da constituição, da configuração (estrutura tridimensional) e das diferentes conformações, formas que uma molécula pode assumir. Surge então um novo problema. Como representar esses modelos no papel?

Há casos, em que a representação da estrutura tridimensional da molécula é fundamental. Por exemplo, as estruturas dos carboidratos diferem apenas na distribuição espacial de átomos idênticos ligados a um mesmo carbono, ou seja, apenas na configuração de carbonos assimétricos. Foi Emil Fischer quem estabeleceu a primeira maneira de representar a configuração dos carboidratos. A representação possui uma série de pré-requisitos: a molécula deve estar na conformação eclipsada, com a cadeia carbônica principal dirigida para baixo e o observador visualizando o modelo pela parte de cima, onde se encontram os átomos ligados aos carbonos da cadeia. Nesta representação, cadeia carbônica é representada por um traço vertical e as hidroxilas por traços horizontais, uma representação simples porém que dá total informação a respeito da estrutura molecular. Hoje, na projeção de Fischer os pré-requisitos são mantidos, porem os átomos ligados à cadeia principal são discriminados, de maneira a ampliar o seu uso para outras classes de compostos.

Várias outras projeções de modelos foram surgindo, ainda no século XIX; $;^{10}$ uso do hexágono e do pentágono para o cicloexano e o ciclopentano, respectivamente, e para representar cadeias abertas, linhas quebradas nas quais os átomos de carbono encontramse nos vértices, como as usadas hoje. No século XX algumas outras projeções de modelos moleculares foram propostas, como a de Natta para representar polímeros com grandes cadeias carbônicas e a de Newman para o estudo de conformações e de interações entre carbonos vizinhos.

Cada uma dessas representações gráficas implica em uma perspectiva de observação do modelo e contém uma série de requisitos necessários para que o leitor entenda a estrutura em questão. $\mathrm{O}$ modelo molecular propiciou uma maneira de se estudar e entender melhor a estrutura molecular invisível a nossos olhos, uma vez que proporcionou uma forma de representá-las. Com o aprendizado dessa forma de representação o químico não precisa mais ter o modelo concreto em suas mãos, ele consegue imaginá-lo a partir da fórmula estrutural desenhada.

Os modelos moleculares e suas representações são de extrema importância, não só na química, como na bioquímica, no estudo de macromoléculas naturais como as proteínas. Eles constituem uma linguagem específica dos químicos.

\section{CONSIDERAÇÕES FINAIS}

Pelo exposto, fica clara a impossibilidade de estudar-se química orgânica sem compreender o significado das várias representações moleculares. Significados esses que nem sempre são apresentados aos alunos e discutidos em sala de aula, durante os cursos de química orgânica no ensino superior. Às vezes, os modelos são 
considerados assunto sabido; outras vezes, são simplesmente ignorados, prejudicando o aprendizado significativo do aluno.

Situação muito mais grave é a que se apresenta no ensino médio quando essas representações estruturais simbólicas são apresentadas sem nenhuma explicação. O aluno associa a molécula do benzeno, por exemplo, a um hexágono com uma bolinha dentro. Esta situação torna o estudo da química orgânica uma memorização de nomes e símbolos que, sem os devidos esclarecimentos, nada têm a ver com a realidade microscópica que eles representam. Da linguagem da química, aprende-se, quando muito, apenas os nomes das coisas, sem maior significado.

Como acabamos de discutir, a aprendizagem da química se caracteriza pela apropriação de uma linguagem específica e apropriada para a descrição dos fenômenos materiais. Precisamos, no entanto, facilitar o aprendizado inicial da mesma se quisermos que os alunos se envolvam com o estudo, condição essencial para o seu sucesso. Para isto temos que elaborar estratégias de ensino apropriadas aos estudantes, estabelecendo relações entre os materiais macroscópicos e suas representações microscópicas, discutindo os modelos químicos em detalhe, ajudando-os a apropriar-se das palavras da química.

Alguns livros mais modernos abordam a química, indo do contexto para o conceito a ser ensinado, mostrando a importância do conhecimento químico a ser adquirido, o que é uma forma de envolver o aluno. Porém, mesmo esses livros, quando tratam da química orgânica, ainda cometem o deslize de apresentá-la de uma forma pouco significativa, sobretudo na questão da representação molecular.
Em função do exposto, clara está a necessidade de investigações em ensino de química orgânica para o grande público e para os futuros químicos, especificamente, das representações das estruturas químicas, em função da importância da química na compreensão do mundo contemporâneo e da participação nas decisões públicas. ${ }^{11}$

A Profa. Helena, com o entusiasmo que lhe era peculiar, certamente aceitaria o desafio de participar de um estudo dessa natureza.

\section{REFERÊNCIAS}

1. Chalmers, A. F.; O que é ciência afinal, Editora Brasiliense: São Paulo, 2000.

2. Maar, J. H.; Pequena história da química, Papa-livros: Florianópolis, 1999, cap. 2.

3. Hoffmann, R.; Laszlo, P.; Angew. Chem., Int. Ed. 1991, 30, 1; Laszlo, P.; A Palavra das Coisas ou A Linguagem da Química, Gradiva: Lisboa, 1995.

4. Vigotski, L. S.; A Construção do Pensamento e da Linguagem, Martins Fontes: São Paulo, 2001.

5. Del Re, G.; Hyle, Int. J. Phil. Chem. 2000, 6, 5.

6. Mortimer, E. F. Em Ciência, ética e cultura na educação; Chassot, A.; Oliveira, R. J., orgs.;. Ed. Unisinos: São Leopoldo, 1998, cap. 4.

7. Chassot, A.; Alfabetização Científica: questões e desafio para a educação, Ed. Unijuí: Ijuí, 2003, cap. 5.

8. Ihde, A. J.; The development of the modern chemistry, Dover: New York, 1984, cap. 12.

9. Oki, M. C. M.; Química Nova na Escola 2007, n ${ }^{\circ} 26,24$.

10. Mayo. P.; Mono and sesquiterpenoids, Interscience: New York, 1956.

11. Santos, W. L. P.; Schnetzler, R. P.; Educação em química: compromisso com a cidadania. Ed. Unijuí: Ijuí,1997. 